\title{
LIFE HISTORIES OF NORTH AMERICAN GEOMETRIDAE.-LIV.
}

\author{
BY HARRISON G. DYAR, WASHINGTON, D. C.
}

Hyperitis trianguliferata Packard. The life history of this species has been described by Professor G. H. French (Can. ent., xviii, 105, I886) from Californian larvae, with four stages. I present my own descriptions, however, as I have noted some points not mentioned by him and the larva has not been otherwise referred to.

Egg. Elliptical, rounded, one diameter less, no flattening nor depression; truncation marked, oblique. Longitudinal ribs low, obscure, straight, few, about six visible on the broad side, joined by cross-striae, forming cells three times as wide as long; ends reticulate Pale yellow; size $\mathrm{I} \times .7 \times .6 \mathrm{~mm}$.

Stage $I$. Head rounded, testaceous, a little darker on the vertex, eje black, mouth brown. Body moderate, not greatly elongate, rapidly looping or held rigid with a thread. Whitish, a broad dorsal band of smoky olivaceous and a still fainter ventral one, scarcely more than a shade. Feet pale; tubercles very small, brownish; setae moderate, glandular tipped; no shields.

Stage II. Head rounded, the lobes full, sordid whitish with black dottings on the lobes and around the mouth; width $6 \mathrm{~mm}$. Body moderate, greenish, shaded with blackish olivaceous dorsally, with subdorsal and lateral lines indicated by white segmentary dashes. a white stigmatal line with black and gray spots, tubercle iv largest on joints 7 and 8 . Venter orange tinted, obscurely lined and marked by blackish blotches at the tubercles. Tubercles roundedly elevated; setae obscure; feet pale with dark lines; a geminate ventral whitish bard.

Stage III. Head whitish with pale brown dots forming bands curved transversely, antennae prominent, pale, ocelli black; width $1.1 \mathrm{~mm}$. Body moderate, the segments enlarged centrally by the conical tubercles, especially joint 7 . Pale brown; subdorsal line broken into white dashes, the longest one on joint 5 , edged with black shading; sides shaded; substigmatal band broad, yellowish white, illy defined but distinct; a paler subventral line; centers of segments subventrally and venter medially black shaded; tubercles conical, black, ii prominent, especially on joint 7 . Feet pale; setae very short; anal shield and leg plates pale.

Stage IV. Head round, cuneiform, the lobes full above, held flatly; light and brown mottled on the sides, pale over the face and vertex; width $1.7 \mathrm{~mm}$. Body cylindrical, joints 2 and 3 depressed, their feet appressed, those of joint 3 erected; straight, stick-like, joint 7 humped dorsally, tubercles ii forming high cones on joints 7 and 9, !ess so on joints 6 and 8 , small on joints 5, 11 and 12 . Whitish green, washed with brown of light and dark; an oblique lateral streak on joints 3 and 4 , the fronts and backs of the high tubercles, irregular marks and blotches on the sides, especially of joints 7 to 9 and a partly continuous subventral band. Ordinary markings lost. Feet of joint to brown behind, pale before; thoracic feet bright red shaded. Faint whitish washed longitudinal lines.

The larvae fed on currant (Ribes sanguineum); bred from eggs obtained at Kaslo, British Columbia. 

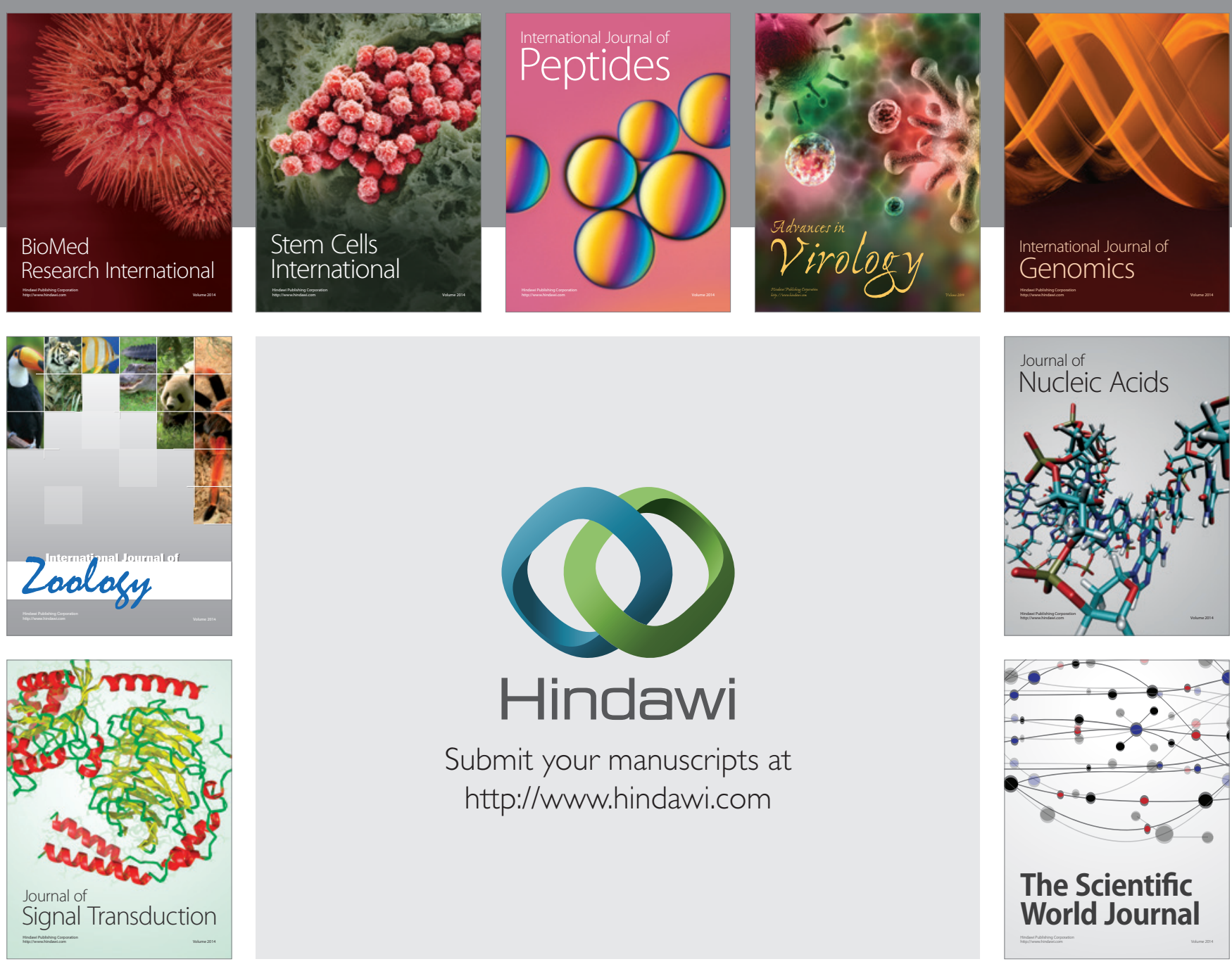

Submit your manuscripts at

http://www.hindawi.com
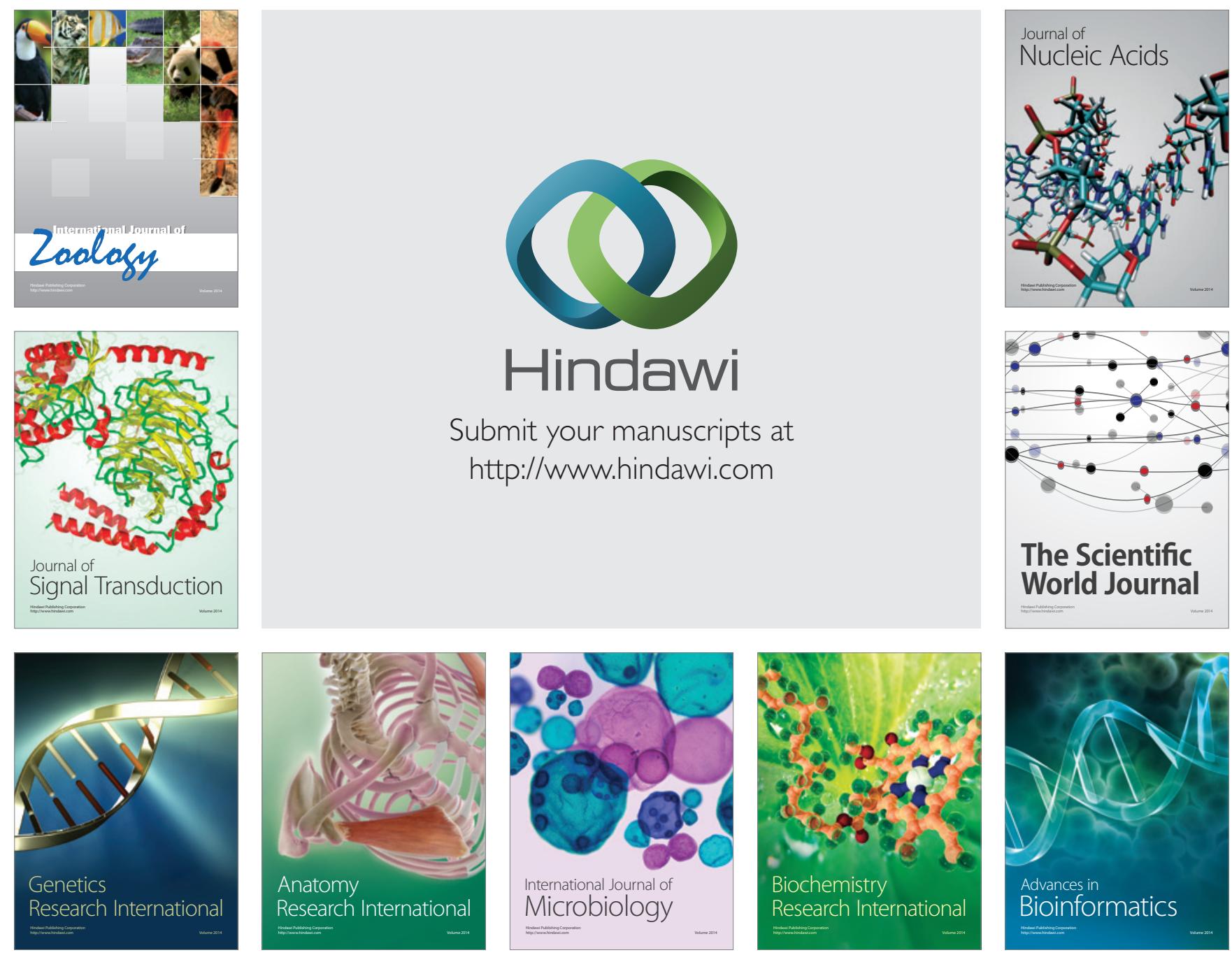

The Scientific World Journal
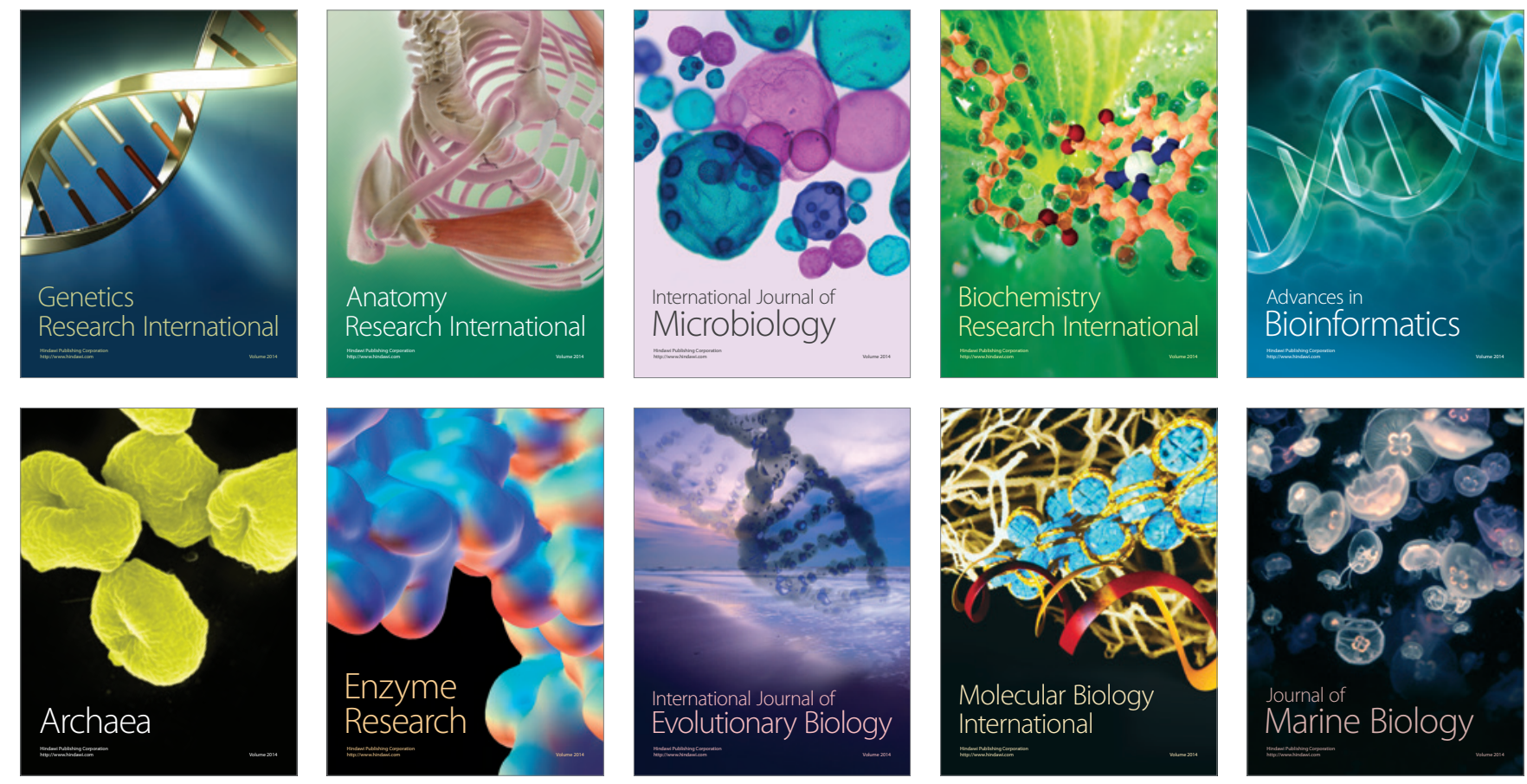